\title{
Lexical Errors in Writing at the End of Primary and Secondary Education: Description and Pedagogical Implications
}

\author{
M. ${ }^{\text {a }}$ Pilar Agustín Llach \\ Universidad de La Rioja
}

Received: 30 April 2013 / Accepted: 4 June 2014

ISSN:1697-7467

\begin{abstract}
In this paper, we present a study which describes and compares the production of lexical errors at the end of two important educational stages: Primary and the compulsory years of Secondary education. Identifying the most frequent lexical error types at each acquisition stage can be very insightful in distinguishing among proficiency levels and establishing lexical benchmarks. Our results show a slight decrease in lexical error production, only significant for direct L1 borrowings. However, they also reveal an increase of misselections and coinages at higher levels. Furthermore, we observed presence of fossilized errors and errors in constructions. Results are interpreted in light of previous research-related literature concerning the evolution of lexical errors along proficiency levels. Finally, some pedagogical implications are suggested to improve the lexical production of Primary and Secondary school learners in order to prevent and remedy the lexical errors they committed. Keywords: lexical error, fossilization, L1 influence, Primary and Secondary education, misselection.
\end{abstract}

Los errores léxicos en la escritura al final de las etapas de primaria y secundaria: descripción e implicaciones pedagógicas

RESUMEN: En este artículo presentamos un estudio que describe y compara la producción de errores léxicos al final de dos importantes etapas educativas: Primaria y Secundaria Obligatoria. Identificar las categorías de errores léxicos más recurrentes en cada estadio puede resultar muy relevante para diferenciar niveles de lengua, así como para establecer puntos de referencia desde el punto de vista del léxico. Nuestros resultados muestran una muy ligera reducción de la presencia de errores léxicos, siendo los préstamos los únicos que disminuyen de manera significativa. Por otro lado, las creaciones léxicas y las selecciones erróneas aumentan su presencia en niveles más altos. También, pudimos observar la presencia de errores fosilizados y de errores en construcciones. Interpretamos los resultados en función investigaciones previas relacionadas con el tema de la evolución de la producción de errores léxicos conforme aumenta el nivel de lengua. Finalmente, ofrecemos algunas implicaciones pedagógicas destinadas a mejorar la producción léxica de alumnos de Primaria y Secundaria, así como a prevenir y remediar los errores léxicos que cometen.

Palabras clave: errores léxicos, fosilización, influencia de la L1, educación Primaria y Secundaria, errores de selección léxica. 


\section{INTRODUCTION}

The end of Primary and the compulsory years of Secondary education represent important milestones in the learners' second language (L2) acquisition process. The L2 proficiency achieved at the end of these educational stages establishes an important benchmark worth describing. Lexical errors are very interesting from this point of view, because they provide researchers with insightful information that help determine the evolution of the lexical profile of learners at these stages. Furthermore, lexical errors might also help in discriminating among proficiency levels.

According to Verspoor et al. (2012), it has been frequently attested that lexical measures change as proficiency increases. They found that the lexicon of the learners changes subtly and slowly across proficiency levels, developing towards more sophistication, accuracy, and fluency. The role of errors in learners' writings is not as straightforward, though. It seems reasonable to think that as learners grow older and their knowledge of the L2 progresses, they will perform better, or in any case differently, than low(er) proficient peers. Thus, different proficiency levels may have varying impacts and consequences in L2 acquisition. Verspoor et al. (2012) believe that it has been proved that, although all learners make errors, the more advanced learner makes fewer errors. However, some other studies (Torras and Celaya 2001, Cenoz 2003, García Lecumberri and Gallardo 2003) show that there is a qualitative change rather than a quantitative one, and that error tallies do not decrease when considered globally. The amount and the type of errors produced vary with age and proficiency (e.g. Lasagabaster and Doiz 2003, Celaya and Torras 2001). It is our intention here to address this issue in the particular case of lexical errors.

The present papers reviews previous studies concerned with the evolution of lexical errors in FL writings across grades. We also delve into the role of L1 influence in lexical error production, and tackle the particular phenomenon of fossilization. The study presented here intends to describe and compare the lexical error profiles of learners at the end of the primary and secondary educational stages.

\section{EvOlution OF LEXICAL ERRORS}

The nature of lexical error development is not straightforward. Different trends can be observed: some errors decrease with L2 proficiency, some increase temporarily, while others show instability and then finally end up disappearing, and other errors fossilize, that is, they become permanent in learners' interlanguage.

As L2 language knowledge increases, the learner incorporates new words, new aspects of already known words, and/or new morphosyntactic norms. Linguistic competence becomes more stable and relationships among linguistic components strengthen. As a consequence, some (lexical) errors disappear, but some other become more pervasive. Some studies (Grant and Ginther 2000, Fernández 1997, Lennon 1991) show a decrease in the production of errors in learners' interlanguage as proficiency increases, together with an increase in text length. In particular, Bardovi-Harlig and Bofman (1989) found a decrease in lexical error production, but not in morphological or syntactic errors, in written texts among students of high proficiency. 
Lexical errors' reduction with time and proficiency is a perception that is not always sustained by empirical evidence. Examination of the interlanguage of very advanced learners has suggests that even they produce many errors, especially of the lexical type (Ambroso 2000, Lennon 1996, 1991). Moreover, the perennial presence, even in very advanced learners' production, of fossilized errors (see e.g. Olsen 1999, Selinker 1972) refutes the universality of the claim: the more proficient, the more accurate. The increasingly more complex and sophisticated production of more proficient learners (Ruiz de Zarobe 2005b, Lasagabaster and Doiz 2003, Fernández 1997) can help account for the apparently counterintuitive result that as proficiency increases errors do not decrease. Several studies have described and compared the errors in the production of advanced learners and of lower proficient learners. They have reached different conclusions. For instance, Hawkey and Barker (2004) and also Grant and Ginther (2000: 141) concluded that the number of word choice errors decreased as proficiency level increased. However, Dagneaux et al. (1998) listed lexical errors as the most frequent in a corpus of advanced learners, highlighting that they are still very frequent.

Verspoor et al. (2012) suggest that lexical changes and organization occur at advanced levels. Specifically, they state that general error production does not help discriminate among proficiency levels, and that only L1 transfer errors show significant decrease. There has been ample research in this line. In a study conducted by Taylor (1975), L1 transfer errors appeared most frequently in the production of intermediate learners. Olsen (1999), Fernández (1997), and LoCoco (1975) also report a higher number of errors attributed to cross-linguistic influence for less proficient learners, although they highlight that the influence of the L1 is present also at more advanced levels. By contrast, Mukattash (1986) determined that L1 influence was more pervasive in advanced learners, and that those errors, which were traceable to L1 influence, were candidates for fossilization. Younger and low proficiency learners resort to their L1 more frequently than more proficient and older learners, especially with regards to use of borrowings (Lasagabaster and Doiz 2003, Wang 2003, Celaya and Torras 2001). Nonetheless, Cenoz (2003) showed that the oldest learners transfer most from their L1, and Sanz (2000) found out that the more proficient the learners are, the more they transfer. Inconclusive findings abound thus in this area of research.

Finally, very few studies have dealt with errors at the construction level in EFL learning contexts. Verspoor et al. (2012) found that errors in constructions were common at advanced levels of proficiency, where sentences become more complex. At lower levels of proficiency, sentences tend to be simple and lack complex constructions. Therefore, construction errors increase in presence at higher levels of proficiency. Consequently, more errors in constructions can be expected at higher levels (cf. Verspoor et al. 2012).

\section{Fossilization ANd SLA}

One of the features that distinguishes between L1 and L2 acquisition situations is the presence of fossilization in SLA. While similar degrees of mastery are achieved in the L1 by native children, L2 use is characterized, though by no means universally, by the occasional persistent presence of some errors or deviant structures, i.e. some L2 errors are never remedied or remedied at a very slow pace, and become fossilized, in spite of exposure to the FL, or of pedagogic interventions. This lack of progression despite exposure to input and practice opportunities was termed fossilization by Selinker (1972). This term has since 
then been widely used in the literature about errors ${ }^{1}$. The fact that learners can communicate effectively, though not accurately, in the L2 may contribute to the phenomenon of fossilization (cf. Richards 2008). However, Han and Odlin (2005: 4) also mention other causes of fossilization apart from communicative skills residing on environmental, social, affective, cognitive or neuro-biological factors.

The most typical examples of fossilization or persistent non-target like performance are probably errors in pronunciation, which give rise to the characteristic "foreign accent" of many L2 learners. However, fossilization can occur in every linguistic domain, syntax, morphology, grammatical aspects, such as tense or aspect, lexico-semantics or pragmatics (Han and Odlin 2005). Research has concentrated on exploring fossilization in grammar (e.g. Lardiere 2005, Odlin, Alonso Alonso and Alonso-Vazquez 2005), but few studies have dealt with lexical fossilization or fossilized lexical errors (e.g. Hyltenstam 1998, Lennon 1991). As Han and Odlin (2005: 5) acknowledge, empirical evidence from investigations regarding fossilization is scarce. Nevertheless, existing studies put forward that L1 influence is a main factor in bringing about fossilization (e.g. Odlin et al. 2005), and that fossilized errors tend to alternate with correct or norm-referenced instances of language use (e.g. Han and Odlin 2005). In this sense, Lakshmanan (2005) believes that corrective feedback or negative evidence might help overcome fossilization and get the language right.

Lexical errors categories may distinguish among proficiency levels. Furthermore, they can serve as lexical profilers for age and stage-ends. Foster-Cohen (2001 in Lakshmanan 2005: 104) talks about the sliding window effect to unveil L2 acquisition developmental stages by looking into what learners can or cannot do. As has been advocated somewhere else (Grant and Ginther 2000: 143) by coding errors of various types, it could be possible to examine how lexical knowledge develops. And thus, use them to discriminate among proficiency levels or FL acquisition stages. In this particular study, we focus on the description of lexical error production at both final stages to then compare both samples. We categorized the lexical errors in order to determine whether there were particular types of lexical errors that were typical for different learning stages.

Guided by previous controversial findings regarding error decrease as proficiency increases and through the need to establish benchmarks for end of educational stage, this study posed the following research questions:

1. What are the most typical lexical errors for learners at grade 6 (end of Primary) and at grade 10 (end of Secondary)?

2. Are there any differences in the amount of lexical error types produced by $6^{\text {th }}$ and $10^{\text {th }}$ graders?

3. Are there persistent non-target like forms or fossilized errors which crop up in grade 6 and grade 10 ?

With the information obtained by the results of the study, we intended to draw some pedagogical implications that would help improve the quality of lexical instruction and enhance foreign language vocabulary acquisition.

\footnotetext{
${ }^{1}$ The notion of fossilization is a complex one, which has given to heated debate in the literature (cf. Han and Odlin 2005). Here, we use the term in a very basic sense to refer to those lexical errors that persist from grade $6^{\text {th }}$ to grade $10^{\text {th }}$.
} 


\section{4. Мethod}

The present study follows a cross-sectional design in which data is taken from two different learner groups at the end of their Primary and compulsory Secondary educational levels. We chose these stage ends because we were interested in comparing lexical error profiles for these benchmarks, which are used as reference for official examinations or requirements.

\subsection{Participants}

Two learner groups make up the study samples. First, 263 learners at the end of Primary education, grade 6 participated in the study. They were between 9 and 10 years old. The second learner group was made up by 86 students at the end of compulsory Secondary education, grade 10 . These students were between 15 and 20 years of age, since some of them had repeated grade. The mother tongue of the students was Spanish.

\subsection{Instruments}

Participants were required to write a letter to a prospect English host family. In the letter, they had to introduce themselves, talk about their family, school, hometown, their hobbies; and any other thing they thought the host family would be interested in about them. Learners had 30 minutes to complete the task. No reference books, dictionaries or any other help was allowed.

\subsection{Analysis and procedures}

Letter writing took place in a regular session in presence of the teacher and the researcher. Writings were typed in into computer readable form and were scrutinized for lexical errors. In particular, we examined production of borrowings, coinages, calques, semantic confusions and misselections. Borrowings are direct insertions of L1 words in the L2 syntax:

- We have a big jardín (Eng. garden)

Coinages or L1 adaptations consist in adapting an L1 word to the L2 graphological, spelling or morphosyntactic norms, so that it looks or sounds like an L2 word:

- My school is very big, it has gym, garden, bibliotec (Eng. library from Span. biblioteca)

Calques, also known as literal translations, are meaning transfers or semantic extensions in which an L1 word or expression is directly translated to the L2 assuming direct meaning equivalence:

- I help you in the works of the house (Eng. help with the household from Span. ayudar con las tareas de la casa)

- I have got very genious (Eng. I get angry easily, lit. Span. Tengo mucho genio)

Semantic confusions imply the mixing of two words that share some semantic features, but not all:

- It is a small village, but it is enjoy (for funny) 
And finally, misselections refer to wrong word form choices or what Laufer (1991) called synforms. Misselections consist in confusion of two words that have very similar form:

- I'm waiting vey exciting (for excited)

We were also interested in the production of a particular type of error which relates to verbal structures and which we termed construction error. This kind of error represents an interface between lexis and grammar and pertains to wrongly chosen or wrongly placed prepositions, wrong verb form or meaning:

- I help with you (for I help you)

We used the SPSS 21 to perform descriptive and inferential analysis.

\section{Results}

In the present study, we wanted to describe and compare lexical error production at the end of Primary and of Secondary education, to identify fossilized errors, and to propose some pedagogical implications

Results report the data for 263 students in grade 6, at the end of primary education and for 86 students at grade 10, at the end of secondary. The following table offers the descriptive results for both grades

Table 1: Mean values for lexical errors

\begin{tabular}{|c|c|c|c|c|c|c|c|c|c|c|c|}
\hline & $\mathrm{N}$ & Borrowing & s.d. & Coinage & s.d. & $\begin{array}{c}\text { Literal } \\
\text { translation }\end{array}$ & s.d. & $\begin{array}{c}\text { Semantic } \\
\text { confusion }\end{array}$ & s.d. & Misselection & s.d. \\
\hline Grade 6 & 263 & .91 & 1.8 & .78 & 1.5 & 1.23 & 1.5 & .80 & 1.2 & .52 & .85 \\
\hline Grade 10 & 86 & .19 & .5 & .94 & 1.3 & .92 & 1.7 & .42 & .65 & .66 & .86 \\
\hline
\end{tabular}

In this data, we can observe several interesting issues worth noticing. Probably, the most notable result is the great decrease in the production of borrowings. Literal translations and semantic confusions also decrease their presence. However, misselections are more frequent in grade 10 than in grade 6. The highest increase is for coinages, which become the most frequent lexical error category at the end of secondary education.

We also conducted a comparison of the order of frequency of each of the lexical error categories at both grades to find out the most and least frequent categories at both stages and check whether these coincide or not. The next table shows these rank orders. 
Table 2: Order of frequency of lexical error categories

\begin{tabular}{|c|l|c|l|c|}
\hline $\begin{array}{c}\text { Order of } \\
\text { frequency }\end{array}$ & \multicolumn{1}{|c|}{ Grade 6 } & \% over total & Grade 10 & \% over total \\
\hline 1 & $\begin{array}{l}\text { Calque/lit. } \\
\text { translation }\end{array}$ & $29 \%$ & Coinage & $30.18 \%$ \\
\hline 2 & Borrowing & $21.45 \%$ & $\begin{array}{l}\text { Calque/lit. } \\
\text { translation }\end{array}$ & $29.81 \%$ \\
\hline 3 & Semantic confusion & $18.85 \%$ & Misselection & $21.1 \%$ \\
\hline 4 & Coinage & $18.49 \%$ & Semantic confusion & $13.1 \%$ \\
\hline 5 & Misselection & $12.2 \%$ & Borrowing & $5.81 \%$ \\
\hline
\end{tabular}

As we can see from this table, the order of frequency of the lexical error categories changes completely, with the percentages of occurrence of the different categories being more evenly distributed at grade 6 than at grade 10. This might point to sharper differences or more instability at grade 10 previous to disappearance of some lexical error category. This instability is typical of (low-)intermediate stages of acquisition. This rank order provides useful information about the deviant lexical productions that shape the typical profile of the different stages.

When all errors are added up, there are moderate differences among the proficiency levels. Total mean values reveal higher lexical error figures for grade 6 writings with 4.23 lexical errors per student versus 3.19 mean instances of lexical errors in grade 10. Within this tendency of slight improvement, we list the figure for students that commit lexical errors altogether. At grade 6, 4.56\% of the inspected writings are error-free; at grade 10, $10.46 \%$ of the participants do not commit any lexical error in their letters. Although very slight, these might be signs that lexical accuracy is beginning to improve, and that at the end of secondary education, learners' writings are slightly more lexically accurate.

We wanted to ascertain whether the differences in mean values for each lexical error category at the grades tested were significant or not. None of the samples met the normality assumption, so non-parametric tests for means comparisons were conducted. The results of the inferential statistics clearly showed that, except for borrowings and to a lesser extent for semantic confusion, no significant differences were found.

Table 3: Inferential statistics for lexical error categories at grades 6 and 10

\begin{tabular}{|l|l|l|l|l|l|}
\hline & Borrowing & Coinage & $\begin{array}{l}\text { Literal } \\
\text { translation }\end{array}$ & $\begin{array}{l}\text { Semantic } \\
\text { confusion }\end{array}$ & Misselection \\
\hline Mann-Whitney U & 8174.500 & 10358.500 & 10600.500 & 9775.500 & 10059.500 \\
Wilcoxon W & 12002.500 & 45074.500 & 14428.500 & 13516.500 & 44775.500 \\
Z & -4.719 & -1.478 & -1.084 & -2.138 & -1.956 \\
Sig. asintót. (bilateral) & .000 & .139 & .278 & .032 & .051 \\
\hline
\end{tabular}


In the process of identifying and categorising lexical errors, we had the opportunity to conduct a more qualitative observation of learners' writings and lexical errors produced. The qualitative analysis of the lexical errors identified lead us to focus on some of those which were found to be especially problematic either because they were very frequent or they were difficult to explain and correct. They have their origin in either L1 literal translation (e.g. direct translation: I wear doing [Eng. I have been doing, literally Llevo haciendo] ${ }^{2}$ ), or in a double equivalent into L1 (e.g. wait/hope translated into esperar in Spanish L1, or know vs. meet all translated into conocer in Spanish).

We felt especially puzzled by a particular error: the confusion of the verbs to be and to have. For instance, using the to be as the auxiliary for the perfect forms $I$ was been in Romania; using the have instead of the auxiliary be: We have hot (L1-based) for It is hot, or using the be as a lexical verb instead of have: You aren't nothing to do for You have nothing to do [in the village], I am one sister her name is Marta for I have one sister; and finally the pervasive use of have when referring age, a clear literal translation from L1 Spanish, e.g. I have got 16 years (I am 16 years old.).

We feel unable to find an explanation to most of these confusions. On some occasions, they can be traced back to the L1; nevertheless, in some other cases, we cannot observe any reference to L1, especially when used as a lexical verb; since these verb uses are clearly distinguished in Spanish L1. This confusion is recurrent in grade 6 and 10, alike, showing fewer instances as grade increases.

A close scrutiny of the writings in grades 6 and 10 reveals some information which is of more qualitative nature and escapes quantitative measurement or raw quantification. Basically, we can find two main trends. First, we could identify the phenomenon of fossilization in our data. We were surprised by the notable amount of errors that kept appearing in grade 10 writings. In particular, frequent errors in grade 6 that are still visible 4 years later at the end of Secondary education can be grouped according to the following etiologies:

1. L1 influence: direct translation
a. I have $\mathrm{X}$ years old
b. Adjective $+\mathrm{s}$
c. Noun + adjective

2. L1 influence: adaptation:

a. Sympatic for friendly

b. Deport for sport

3. L1 influence: incongruence L1-L2 and semantic confusion in L2 (learners do not know there is another semantically similar word and assume semantic and pragmatic equivalence L1-L2):

a. Wait for hope

b. Fathers for parents

c. Sons for kids

d. Brothers for siblings

e. Class for classroom

\footnotetext{
${ }^{2}$ This error might also be interpreted as a construction error.
} 
4. Failure to notice correct spelling derived from L2 overgeneralization:

a. Beautifull for beautiful (beauty + full)

$b$. Whit for with (overgeneralized from which and other wh-forms)

c. Live for life

5. L2 semantic confusion:

a. Very for much

Second, we observed that despite lack of lexical errors in specific writings, especially those at grade 10, they were still of poor quality. Sentences became more complex as did the ideas expressed, and errors in verb use start to appear. Additionally, we could identify some language problems that could not be classified into any of the categories of lexical errors proposed. These inconsistencies in language use had mostly to do with the arguments of the verb, so we decided to term them "construction errors" (cf. Goldberg e.g. 2006). Furthermore, these were generated by L1 influence or incongruence between L1 and L2 systems. Some examples of these are:

- Problems with prepositions: I donate at poor, I meet with my friends, I like listening music,

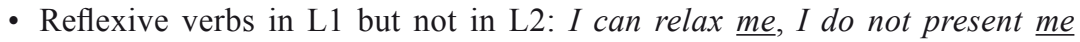

- Verb transitivization: I am writing to introduce you myself,

- Phrase to express purposes: I meet friends for play, I am waiting for see you,

- Human objects preceded by to: He visit to me always,

- Verb arguments subject animate/inanimate: Films romantic doesn't love with me

This line of inquiry is very interesting and opens up a possible new link between lexical errors and pedagogical grammar, construction grammar, or cognitive linguistics.

\section{Discussion}

In the present study, we wanted to explore the evolution of lexical error production and with it the evolution of the mechanisms learners use when they lack lexical knowledge and want to transmit some message. Identifying the most frequent categories at each stage end and comparing results can inform about the lexical competence of learners at the end of Primary and of Secondary education. Fossilized errors can also give interesting insights into the lexical benchmark of these stages.

A non-significant lexical error decrease was found. This is in line with previous studies which show no significant decrease of error production despite increase in proficiency (Ruiz de Zarobe 2005a and b, Naves and Miralpeix 2002, Torras and Celaya 2001). Interpretations for this apparently counterintuitive finding range from the increasing difficulty of the task to be performed to the use of more complex linguistic resources in written production at higher grades. We can reasonably argue that, in our study, the writing task is perceived as easier at grade 10, however, the topic of the composition might leave little room for improvement and lexical variation or lexical sophistication. Other explanations of a lack in the decrease of lexical error production might point to learners reaching a plateau where they are communicatively effective for classroom purposes, at least, and thus stop progressing lexically 
(cf. Richards 2008). It is an informally observed phenomenon that Spanish L1 learners of FL at low-intermediate levels have a hard time going up a level when they perceive they can communicate. We could also speculate that proficiency manifests with syntactic accuracy, or fluency rather than with lexical accuracy at this particular developmental stage. Lack of learning of general composing strategies and L1 literacy transfer may be hindering the learners from the benefits drawn from writing practice (cf. Lasagabaster and Doiz 2003).

Learners in $10^{\text {th }}$ grade, with a more advanced level of language knowledge, continue to make lexical errors of all types. The fact that $10^{\text {th }}$ grade learners of EFL are still of limited linguistic and lexical competence may also account for this error production.

In general terms, we obtained no significant changes in lexical error production from grade 6 to grade 10, but for borrowing production. However, a closer examination of the results profiles two different pictures for grade 6 and grade 10 lexical error production behaviours. These have to do with the different lexical error types prominent at the two grades and with how they evolve from one grade to the other. Different proficiency stages are characterized by different error types (cf. Dagneaux et al. 1998, Lasagaster and Doiz 2003, Verspoor et al. 2012). Thus, an increase in the production of certain types of lexical errors is a sign of development and not of lack of pogress in acquisition (cf. Fernández 1997). Different causes such as lexicon organization, lexical repertoire, compensatory strategy use might account for this varied nature of lexical error production.

In the present study, borrowings and literal translations were the most frequent categories at the end of Primary education. By the end of Secondary education coinages and misselections take over the floor of borrowings with calques or literal translations keeping a prominent position.

In the following paragraphs, we explore and interpret the evolution of the different lexical error categories along the Secondary education time span.

Borrowings decrease significantly. This result is not surprising since it reproduces previous findings: that age and proficiency contribute to borrowing reduction (e.g. Bouvy 2000, Celaya and Torras 2001, Lasagabaster and Doiz 2003, Rokita 2006, Celaya and Ruiz de Zarobe 2010). Our result confirms that recourse to borrowings is a primary mechanism to compensate for lack of lexical knowledge (to fill the (knowledge) gap; cf. Bouvy 2000 who calls borrowings "gap-fillers") and that it is abandoned with age and L2 proficiency. Students develop a higher linguistic awareness and realize they are dealing with two systems (L1 and L2), they show a clearer language differentiation. Evidence of this is the fact that learners write the borrowings between inverted commas, brackets, in capital letters or marking the L1 word in any other way. We can conclude, thus, that in our data borrowing proceeds consciously as a device to compensate for lack of lexical knowledge as a compensatory communication strategy. Borrowing in our data is temporary and evolving; it depends on learners' levels of linguistic and lexical knowledge and on communicative demands (cf. Bouvy 2000:153).

Semantic confusions also decrease notably reaching almost significant levels. This runs counter to some previous studies (Ringbom 2001), which showed that semantic confusions are more typical of more advanced learners. Nevertheless, Singleton (1999) believes that semantic confusions can be thought to be semantic overextensions of the words learners know; and these overextensions of meaning are also very typical of the early stages of lexical/language acquisition in the native language. In many cases the semantic confusion does 
not derive from a failure in choosing the correct word between two, but rather from the use of the only word the learner knows. This word must bear some semantic resemblance with the intended word. Thus, we tend to believe that as learners gain age and L2 proficiency they show higher development of lexico-semantic competence. Learners start to fix the link between meaning/lema and concept, and consequently, confusions get reduced.

Literal translations slightly decrease their presence from grade 6 to 10 . This might show a better lexico-semantic competence. However, they are still pervasive at the end of Secondary education. Some studies have found calques, literal translations or equivalence errors, to be very frequent in the production of adult learners (Ambroso 2000). We dare speculate that this compensatory communication strategy is probably applied unconsciously, because learners seem to believe that the words they are calquing are in fact English words, contrary to what had happened before with borrowings.

Coinages or L1 adaptations increase confirming thus previous studies that this meaning searching or communication strategy is very popular among more proficient learners (cf. Celaya and Ruiz de Zarobe 2010, Ringbom 2006, 2001). This may be pointing to a better assimilation of spelling, pronunciation, morphosyntactic development, and higher degrees of creativity. Coinage errors are very illustrative of the lexical acquisition process and show themselves as a creative process. Coinages imply therefore, some knowledge of the orthographic or phonetic conventions of the target language and a generalization of them. The ability of Secondary school learners to analyse and dissect language into parts might explain the more frequent appearance of coinages in those learners.

This coinage phenomenon seems to be a conscious strategy with learners trying to make use of the only knowledge they dispose of to communicate. The psycholinguistic origin of coinages may lie in the close distance between Spanish L1 and English L2 lexis, which often results in successful lexical creations (i.e. cognates), e.g.:

- contribución (Sp.) $\rightarrow$ contribution (Eng.),

- proceso (Sp.) $\rightarrow$ process (Eng.),

However, some other times this strategy fails and gives rise to a lexical error of the coinage type:

- I got colch of Bart Simpson (Sp. colcha, Eng. eiderdown)

-What's asignatures is Peter \& Helen's favourites? (Sp. asignatura, Eng., subject).

Misselections increase with age and proficiency. Zughoul (1991) and Dušková (1969) also identified confusions of similar forms in their data of advanced level learners. Learners at the end of Secondary education have a larger lexical repertoire, but this is still unstable and not yet completely established. "Easy" words and words that are apparently known seem to be confused with other that look or sound similarly. This might have to do with the incongruence between spelling and pronunciation, and with the peculiar English spelling. The more words a learner has available in the mental lexicon, the higher the possibility for confusion of formally similar words. This is in line with Laufer's claim (1991: 323) that learners who formally confuse words have a vocabulary good enough to communicate and comprehend language which is not too difficult. Finally, the claim made by McWhinney (2005) that children's ability to pick up new lexical items is limited can help explain the increase of misselections and coinages with age and grade from the end of Primary to the end of Secondary. 
As fossilized errors are concerned, interpretation of results goes in line with previous research findings. An interesting issue about these fossilized errors is that they alternate with correct forms, e.g. I am 16 years old, in learners' writings. This instability is a typical characteristic of this type of persistent non-target like forms, together with L1 origin. Lack of explicit lexical knowledge, of linguistic awareness and of understanding of some L2 concepts (e.g. much/many vs. very) can also be in the root of fossilization. The fact that our learners are still developing their cognitive skills may help understand this interpretation.

These pervasive or fossilized errors put forward that i) fossilization is local and not global, learners keep on progressing in some lexical areas and other linguistic domains, but have problems with some particular lexical errors: misselections, spellings, semantic confusions of particular words, ii) fossilization can happen at any stage of the SLA process and can help identify what learners can and cannot do at that particular age and stage (cf. Han and Odlin 2005: 16). Richards (2008) acknowledges the existence of a plateau beyond which improvement of accuracy falls really difficult. Fossilized errors, notable fluency or communicative skills, poor accuracy, and a limited vocabulary range are typical of this plateau stage. Moreover, Richards (2008) believes that communicative approaches are partly responsible for fossilization, where the development of fluency at times happens at the expense of accuracy. Although, we are far from having evidence to prove this claim, we agree that the communicative teaching approach of our participants can be a partial explanation of their fossilized errors.

Considering constructions or errors in verbal use, our data seems to echo Verspoor et al.'s (2012: 258) findings in that new constructions are more frequent at higher proficiency levels and they are used inconsistently and incorrectly at the beginning. Our data shows that more proficient writers use some (new) constructions, although still imperfectly; probably due to their yet limited proficiency. Verspoor et al. (2012: 258) found that simpler ones gradually disappear and more complex ones appear. They argue that this is so because at lower levels of proficiency, learners are focusing on acquiring enough words and chunks to be able to form more complex constructions. We can only speculate that this tendency will also be expected with our learners.

\subsection{Pedagogical Implications}

Together with the frequent claim for the need to teach vocabulary explicitly and to conduct error correction and remedy programmes that help improve learners' lexical accuracy, we propose an instruction approach that focuses on the specific areas spotted as problematic and the errors that are liable to become fossilized.

Misselections, literal translations, and coinages or lexical creations appear to be the categories that cause more problems for learners at the end of Secondary education. Moreover, the particular lexical errors, which are pervasive in learners' writings from grade 6 to grade 10 despite longer exposure to EFL, also need to be treated explicitly. Explicit instruction and intentional learning can combine with a contrastive approach where the L1 and L2 are compared and similarities and differences put forward, even providing students with negative evidence. This language contrast can be very helpful, since many lexical errors have their origin in L1 influence. Additionally, recourse to L1 can also have positive results, e.g. cognates. 
McWhinney (2005: 151) proposes three Basic Compensatory Strategies, as he calls them, to remedy or overcome fossilized errors: 1) input maximization through dictionary and grammar use, classes, media exposure or social interchanges; 2) recoding, which involves the construction of new images for new words or phrases, e.g. orthographic recoding from auditory, L1 into L2 (semantic and orthographical), and finally, 3) he recommends resonance, a strategy which consists in establishing connections between word forms and meanings, and related to L1 equivalents; so that they can be committed more easily to memory (e.g. keyword technique, real or fanciful connections). We believe with McWhinney (2005) that these strategies can also be helpful for our learners to cope with their learning challenge and to maximize their full learning potential.

Rule generalization and induction can also be very helpful in fostering subsequent implicit acquisition by increasing noticing. Thus, teachers should focus on promoting teaching approaches and strategies that enhance inference. Noticing and output hypothesis have widely been acknowledged as necessary conditions to turn receptive competence into production (Richards 2008). In this sense, we agree with Richards (2008: 7) who states that to address fossilization, instruction should be more explicit, teachers should adopt a focus on form approach aimed at raising consciousness and noticing, and finally propose activities of stretched output to make learners restructure their production making it more complex through communication and attention to linguistic form. Rehearsing, downgrading the difficulty of the task, or repeating the task can help improve accuracy (Richards 2008). Another key issue put forward by Richards (2008) is the necessity to help learners increase their vocabulary by learning more words. Meaning guessing from context, inference, morphological or semantic analysis (e.g. of the pedagogical grammar type), learning words in semantic fields, alphabetically, include collocations and chunks or fixed expressions to sound more natural are activities highly recommended to prevent and remedy lexical errors, as those found in our data.

Finally, this study has put forward that both formal and semantic errors are pervasive at the end of Secondary education, which points to an organization of the mental lexicon which makes use of both formal and semantic connections. Thus, committing words to memory should happen through enhancing both mechanisms of establishing links: formal and semantic.

\section{Conclusion}

The intention of this study was to shed light on the types of lexical errors that occur at the end stages of Primary and of Secondary education, with a special focus on those that are persistent over time, and thus, tend to become fossilized in spite of 4 years of EFL formal and communicative instruction. Hopefully, these results and corresponding interpretation will enable teachers to identify the language problems that must be tackled in the classroom at each particular educational stage. Furthermore, teaching practitioners are informed about the lexical items which need to be recycled until awareness is raised to reduce the risk of fossilization. In addition, an understanding of the results of this study can help refine teachers' expectations about what lexical competence students can develop during the Primary and Secondary educational stages, and thus direct teachers to adopt teaching programs and strategies that are more successful in pedagogical terms. 
The explanation of the varied nature of our results points to lexical error categories varying in the process of language development and the stages through which it progresses. Some lexical error categories seem to discriminate between proficiency levels on the whole, with borrowings being typical of lower stages and coinages and misselections increasing their presence as proficiency augments. Some writings had no errors but contained only very simple constructions; others had a great many errors, especially in more complex constructions. Additionally, our data can lead us to think of a co-existence of formal and semantic organization of the lexicon, which is word-dependent.

In sum, it seems reasonable to expect learners to keep on committing lexical errors along their way of acquiring the target language. Errors are inevitable and necessary for the development of language. Before mastering any lexical item completely, it will be prey to some type of error. In this sense, lexical accuracy may be liable to distinguish among proficiency levels.

\section{Acknowledgements}

This research study was conducted under the auspices of research project FFI 201019334 funded by the Spanish MICINN.

\section{ReFERENCES}

Ambroso, S. (2000). "Descripción de los errores léxicos de los hispanohablantes: análisis de la producción escrita de IT, el certificado de competencia general en italiano como L2", in E. de Miguel, M. Fernández Lagunilla, and F. Cartoni (eds.), Sobre el lenguaje: miradas plurales y singulares. Madrid: Arrecife, 53- 72.

Bardovi-Harlig, K. and Bofman, T. (1989). "Attainment of syntactic and morphological accuracy by advanced language

learners" in Studies in Second Language Acquisition, 11: 17-34.

Bouvy, C. (2000). "Towards the construction of a theory of cross-linguistic transfer", in J. Cenoz and U. Jessner (eds.),

English in Europe. The acquisition of a third language. Clevedon: Multilingual Matters, 143-156.

Celaya, M.L. and Torras, M.R. (2001). L1 influence and EFL vocabulary: do children rely more on L1 than adult

learners?in Proceedings of the 25th AEDEAN Meeting. December 13-15, University of Granada, 1-14.

Celaya, M.L. and Ruiz de Zarobe, Y (2010). "First languages and age in CLIL and non-CLIL contexts" in International

CLIL Research Journal 1 (3), available from: http://www.icrj.eu/13/article6.htm, accessed 11 January, 2013

Cenoz, J. (2003). "The Influence of Age on the Acquisition of English: General Proficiency, Attitudes and Code

Mixing”, in M.P. García Mayo and M.L. García Lecumberri (eds.), Age and the Acquisition of English as a Foreign Language. Clevedon: Multilingual Matters, 77-93. 
Dagneaux, E., Denness, S. and Granger, S. (1998). "Computer-aided error analysis" in System 26: $163-174$.

Dušková, L. (1969). "On Sources of Errors in Foreign Language Learning” in IRAL, 7:11-35.

Fernández, S. (1997). Interlengua y análisis de errores en el aprendizaje del español como lengua extranjera. Madrid: Edelsa.

Foster-Cohen, S. (2001). "First language acquisition...Second language acquisition: What's Hecuba to him or he to Hecuba?"' in Second Language Research, 17,4: 329-344.

García Lecumberri, M.L. and Gallardo, F. (2003). "English FL Sounds in School Learners of Different Ages", in M.P. García Mayo and M.L. García Lecumberri (eds.), Age and the Acquisition of English as a Foreign Language. Clevedon: Multilingual Matters, 115-135.

Goldberg, A. (2006). Constructions at Work: the nature of generalization in language. Oxford University Press.

Grant, L. and Ginther, A. (2000). "Using Computer-Tagged Linguistic Features to Describe L2 Writing Differences" in Journal of Second Language Writing, 9, 2: 123-145.

Han, Z.H. and Odlin, T. (eds.) (2005). Studies of Fossilization in Second Language Acquisition. Clevedon, U.K.: Multilingual Matters.

Hawkey, R. and Barker, F. (2004). "Developing a common scale for the assessment of writing" in Assessing Writing, 9: 122-159.

Hyltenstam, K. (1988). "Lexical characteristics of near-native second-language learners of Swedish" in Journal of Multilingual and Multicultural Development, 9: 67-84.

Lakshmanan, U. (2005). "Child Second Language Acquisition and the Fossilization Puzzle", in Z. Han and T. Odlin (eds), Studies of Fossilization in Second Language Acquisition, Clevedon, U.K.: Multilingual Matters, 100-133

Lasagabaster, D. and Doiz, A. (2003). "Maturational Constraints on Foreign-language Written Production", in M.P. García Mayo and M.L. García Lecumberri (eds.), Age and the Acquisition of English as a Foreign Language. Clevedon: Multilingual Matters, 136-160.

Lardiere, D. (2005). "Establishing ultimate attainment", in Z. Han and T. Odlin (eds), Studies of Fossilization in Second Language Acquisition, Clevedon, U.K.: Multilingual Matters, 35-55.

Laufer, B. (1991). "Some properties of the Foreign Language Learner's Lexicon as Evidenced by Lexical Confusions" in IRAL, 29, 4: 317-330.

Lennon, P. (1991). "Error and the very advanced learner" in IRAL, 29, 1: 31-43.

Lennon, P. (1996). "Getting 'easy' verbs wrong at the advanced level" in IRAL, 34 (1): 23-36.

LoCoco, V. (1975). "An Analysis of Spanish and German Learners' Errors" in Working Papers in Bilingualism, 7: 96-124.

McWhinney, B. (2005). "Emergent Fossilization", in Z. Han and T. Odlin (eds), Studies of Fossilization in Second Language Acquisition, Clevedon, U.K.: Multilingual Matters, 134-156.

Mukattash, L. (1986). "Persistence of Fossilization" in IRAL, 24: 187-203.

Naves, T. and Miralpeix, I. (2002). "Short-Term Effects of Age and Exposure on Writing Development", in I. Palacios

Martínez, M.J. López Couso, P. Fra López, and Seoane Posse, E. (eds.), Fifty Years of English Studies in Spain (1952-2002). A Commemorative Volume. Actas del XXVI Congreso de AEDEAN. Santiago de Compostela, 12-14 diciembre 2002, 407-416.

Odlin, T.; Alonso Alonso, R. and Alonso-Vázquez, C. (2005). "Fossilization in L2 and L3", in Z. Han and T. Odlin (eds), Studies of Fossilization in Second Language Acquisition, Clevedon, U.K.: Multilingual Matters,83-99.

Olsen, S. (1999). "Errors and compensatory strategies: a study of grammar and vocabulary in texts written by Norwegian learners of English" in System, 27: 191-205. 
Richards, J. (2008). Moving Beyond the Plateau From Intermediate to Advanced Levels in Language Learning. Cambridge University Press: New York.

Ringbom, H. (2001). "Lexical Transfer in L3 Production" in J. Cenoz, B. Hufeisen and U. Jessner (eds.), Cross-linguistic Influence in Third Language Acquisition: Psycholinguistic Perspectives. Clevedon: Multilingual Matters, 59-68.

Ringbom, H. (2006). "The Importance of Different Types of Similarity in Transfer Studies", in J. Arabski (ed.). Cross-linguistic Influences in the Second Language Lexicon. Clevedon: Multilingual Matters, 36-45.

Rokita, J. (2006). "Code-mixing in Early L2 Lexical Acquisition”, in J. Arabski (ed.), Cross-linguistic Influences in the Second Language Lexicon. Clevedon: Multilingual Matters, 177-190.

Ruiz de Zarobe, Y. (2005). "Perspectiva longitudinal de la edad en producción escrita" in Proceedings of the II Simposio Internacional de Bilingüismo: 333-341.

Sanz, C. (2000). "Bilingual education enhances third language acquisition: Evidence from Catalonia" in Applied Psycholinguistics, 21, 1: 23-44.

Selinker, L. (1972). "Interlanguage" in IRAL, 10: 209-230.

Singleton, D. (1999). Exploring the Second Language Mental Lexicon. Cambridge: CUP.

Taylor, B. (1975). "The use of overgeneralization and transfer learning strategies by elementary and intermediate students of ESL"in Language Learning, 25, 1: 73-107.

Torras, R.M. and Celaya, M.L. (2001). "Age-related Differences in the Development of Written Production. An Empirical Study of EFL School Learners" in IJES, 1, 2: 103-126.

Verspoor, M., Schmid, M.S., Xu, X. 2012. A dynamic usage based perspective on L2 writing. Journal of Second Language Writing 21: 239-263

Wang, L. (2003). "Switching to first language among writers with differing second-language proficiency" in Journal of Second Language Writing, 12: 347-375

Zughoul, M. R. (1991)."Lexical Choice: Towards Writing problematic Word Lists" in IRAL, 29: 45-60. 